Article

\title{
Intramuscular Fatty Acids in Meat Could Predict Enteric Methane Production by Fattening Lambs
}

\author{
Francisco Requena Domenech ${ }^{1}{ }^{\complement}$, Pilar Gómez-Cortés ${ }^{2, *}{ }^{\oplus}$, Silvia Martínez-Miró ${ }^{3}{ }^{\oplus}$, Miguel Ángel de la Fuente $^{2}$, \\ Fuensanta Hernández ${ }^{3}\left[\right.$ and Andrés Luis Martínez Marín ${ }^{4}$ (i) \\ 1 Departamento de Biología Celular, Fisiología e Inmunología, Universidad de Córdoba, Ctra. Madrid-Cádiz \\ km 396, 14071 Córdoba, Spain; v02redof@uco.es \\ 2 Instituto de Investigación en Ciencias de la Alimentación, Consejo Superior de Investigaciones \\ Científicas (CSIC), Nicolás Cabrera 9, 28049 Madrid, Spain; mafl@if.csic.es \\ 3 Departamento de Producción Animal, Campus Mare Nostrum, Universidad de Murcia, 30100 Murcia, Spain; \\ silviamm@um.es (S.M.-M.); nutri@um.es (F.H.) \\ 4 Departamento de Producción Animal, Universidad de Córdoba, Ctra. Madrid-Cádiz km 396, \\ 14071 Córdoba, Spain; pa1martm@uco.es \\ * Correspondence: p.g.cortes@csic.es; Tel.: +34-91-001-79-00; Fax: +34-91-001-79-05
}

\section{check for}

updates

Citation: Requena Domenech, F.; Gómez-Cortés, P.; Martínez-Miró, S.; de la Fuente, M.Á.; Hernández, F.; Martínez Marín, A.L. Intramuscular Fatty Acids in Meat Could Predict Enteric Methane Production by Fattening Lambs. Animals 2021, 11, 2053. https://doi.org/10.3390/ ani11072053

Academic Editors: Ramón Arias and Adriana Bonanno

Received: 21 April 2021

Accepted: 6 July 2021

Published: 9 July 2021

Publisher's Note: MDPI stays neutral with regard to jurisdictional claims in published maps and institutional affiliations.

Copyright: (c) 2021 by the authors. Licensee MDPI, Basel, Switzerland. This article is an open access article distributed under the terms and conditions of the Creative Commons Attribution (CC BY) license (https:/ / creativecommons.org/licenses/by/ $4.0 /)$.
Simple Summary: The rearing of ruminant animals is an environmental issue related to greenhouse gas emissions, mainly methane. In the current study, a regression analysis was carried out to obtain a regression equation able to successfully estimate methane production of lambs fattened under intensive feeding systems from their meat fatty acid profile and average body weight during the fattening period. The optimized model exhibited high precision, accuracy and reproducibility. It showed a clear relationship between methane emissions and the fatty acid profile of lamb meat. Our predictive model indicates that fatty acid contents in intramuscular fat could be used to establish the environmental footprint of meat from ruminants.

Abstract: Methane $\left(\mathrm{CH}_{4}\right)$ emissions pose a serious problem for the environmental sustainability of ruminant production. The aim of the present study was to explore the usefulness of the intramuscular fatty acid (FA) profile to estimate $\mathrm{CH}_{4}$ production of lambs fattened under intensive feeding systems. A statistical regression analysis of intramuscular FA derived from ruminal metabolism was carried out to assess the best predictive model of $\mathrm{CH}_{4}$ production $(\mathrm{g} / \mathrm{d})$ in lambs fed with different diets. $\mathrm{CH}_{4}$ was calculated with three distinct equations based on organic matter digestibility (OMD) at maintenance feeding levels. The OMD of the experimental diets was determined in an in vivo digestibility trial by means of the indicator method. Regression models were obtained by stepwise regression analysis. The three optimized models showed high adjusted coefficients of determination $\left(\mathrm{R}^{2}\right.$ adj $\left.=0.74-0.93\right)$ and concordance correlation coefficients (CCC $\left.=0.89-0.98\right)$, as well as small root mean square prediction errors $(\mathrm{RMSPE}=0.29-0.40 \mathrm{~g} / \mathrm{d}$ ). The best single predictor was vaccenic acid (trans-11 C18:1), a bioactive FA that is formed in the rumen to a different extent depending on dietary composition. Based on our data and further published lamb research, we propose a novel regression model for $\mathrm{CH}_{4}$ production with excellent outcomes: $\mathrm{CH}_{4}(\mathrm{~g} / \mathrm{d})=-1.98( \pm 1.284)-0.87$ $( \pm 0.231) \times$ trans-11 C18:1 $+0.79( \pm 0.045) \times B W\left(R^{2}{ }_{\text {adj }}=0.97 ; \mathrm{RMSPE}=0.76 \mathrm{~g} / \mathrm{d} ; \mathrm{CCC}=0.98\right)$. In conclusion, these results indicate that specific intramuscular FA and average BW during fattening could be useful to predict $\mathrm{CH}_{4}$ production of lambs fed high concentrate diets.

Keywords: fatty acids; meat; methane; lambs; vaccenic acid

\section{Introduction}

Nowadays, the environmental impact of the livestock sector in the form of greenhouse gas emissions $(\mathrm{GHG})$, namely, nitrous oxide $\left(\mathrm{N}_{2} \mathrm{O}\right)$, carbon dioxide $\left(\mathrm{CO}_{2}\right)$ and methane $\left(\mathrm{CH}_{4}\right)$ is of great concern worldwide. Considering its global warming potential in terms of 
$\mathrm{CO}_{2}$ equivalents, $\mathrm{CH}_{4}$ represents $44 \%$ of the total GHG emissions of the livestock supply chain or $4 \%$ to $6.4 \%$ of the global anthropogenic GHG emissions [1,2]. Cattle and small ruminants contribute $65 \%$ and $6.5 \%$, respectively, of GHG emissions in the livestock sector and enteric $\mathrm{CH}_{4}$ is about one-half of those emissions [1]. Thus, enteric $\mathrm{CH}_{4}$ emissions pose a serious problem for the environmental sustainability of ruminant production.

Enteric $\mathrm{CH}_{4}$ is a by-product of microbial fermentation of feed in the rumen and the hindgut of farm animals. Microbial digestion releases volatile fatty acids, $\mathrm{CO}_{2}$ and hydrogen $\left(\mathrm{H}_{2}\right)$. Archaea methanogens produce $\mathrm{CH}_{4}$ from $\mathrm{CO}_{2}$ and $\mathrm{H}_{2}$, which have higher availability under feeding conditions that promote more active protozoa and fibrolytic bacteria populations [3]. In ruminants, it is estimated that around $2-12 \%$ of diet gross energy (GE) is lost in enteric $\mathrm{CH}_{4}$, depending largely on diet chemical composition and digestibility $[4,5] . \mathrm{CH}_{4}$ is mostly produced in the rumen and released into the atmosphere through the mouth and nostrils, with direct $\mathrm{CH}_{4}$ rectal emissions accounting for only $3 \%$ of the total [6].

As a result of such environmental concerns, many regression equations have been developed to predict enteric $\mathrm{CH}_{4}$ emissions from ruminant species, either in terms of $\mathrm{CH}_{4}$ yield (g/kg dry matter intake) or production (g or MJ/d) to evaluate different $\mathrm{CH}_{4}$ mitigation strategies. Most of the predictors used in these equations are based on animal or dietary composition [7-12], and also milk fatty acid (FA) profile in dairy ruminants [13-16], since there is an underlying relationship between diet and ruminal microbial population as well as an inherent association between ruminal lipid metabolism and milk FA profile [17]. Thus, it might be hypothesized that if milk FA profile can be related to $\mathrm{CH}_{4}$ emission in dairy ruminants, the intramuscular fat (IMF) FA profile of ruminants may also be related to $\mathrm{CH}_{4}$ production. However, to our knowledge, there is no available information on this subject.

In a recent paper, we showed that the intramuscular FA profile of meat could be a useful tool to monitor the feeding background of lambs entering the food supply chain [18]. The aim of the present study was to further explore the usefulness of the intramuscular FA profile to estimate the environmental impact of intensive lamb raising in terms of $\mathrm{CH}_{4}$ production.

\section{Materials and Methods}

This work was carried out with data from previous studies, the main results of which have been published elsewhere $[19,20]$. Briefly, a total of 105 intact male lambs of the Manchega breed with an initial bodyweight (BW) of $13.9 \pm 1.7 \mathrm{~kg}$ and $35 \pm 7$ days old were randomly allocated to 15 straw-bedded pens at a commercial farm. Each pen had its own water and feed troughs and a straw rack. Animals had free access to water, concentrate feed and cereal straw during the whole experimental period. The pens were randomly allocated to one of three treatments (five replicates per treatment), which differed in the composition of the concentrate that was fed (Table 1): Control (CON), Camelina (CAM), and Fibrous (FIB). The concentrates were mixed and steam pelleted in a commercial feed mill (Iniciativas Alimentarias S.A., Ciudad Real, Spain). Diet composition was determined by usual procedures [21,22] and diet GE was calculated from chemical composition [11]. Average BW and concentrate intake per pen were recorded weekly for 6 weeks. Average daily dry matter intake (DMI, g/day) was calculated for each pen assuming that barley straw represented $5 \%$ of total DMI [23].

On day 42 of the trial, two lambs per pen (i.e., 10 lambs from each experimental treatment) with the final BW closest to the average pen BW, were tagged to track their carcasses. Then, all animals were sent to a commercial abattoir for slaughter. Samples of Longissimus thoracis muscle were obtained for intramuscular FA analysis after 6 days of aging at $4{ }^{\circ} \mathrm{C}$. IMF was extracted following the Bligh and Dyer procedure [24] adding BHT as antioxidant, and total lipids were preserved in amber vials frozen at $-17^{\circ} \mathrm{C}$ until derivatization. Fatty acids were derivatized to methyl esters by base-catalyzed methanolysis and quantified by gas chromatography with an Agilent model $6890 \mathrm{~N}$ network system (Palo Alto, CA, USA) 
fitted with an autoinjector, a flame ionization detector (FID) and a CP-Sil 88 fused silica capillary column (100 m 0.25 mm i.d., Varian, Middelburg, The Netherlands), as described by Gómez-Cortés et al. [18,20]. A total of 59 FA were identified and quantified in lamb IMF. Eleven FA were selected for the statistical regression study (Table 2) based on their well-known relationship with ruminal bacteria metabolism $[25,26]$.

Table 1. Chemical composition (\%) and gross energy content $(\mathrm{MJ} / \mathrm{kg})$ of the experimental diets (values on dry matter basis).

\begin{tabular}{cccc}
\hline \multirow{2}{*}{ Parameters } & \multicolumn{3}{c}{ Treatments $^{\mathbf{1}}$} \\
\cline { 2 - 4 } & CON & CAM & FIB \\
\hline Ash & 6.3 & 7.1 & 9.1 \\
Crude protein & 17.6 & 17.5 & 17.8 \\
Crude fat & 4.8 & 4.6 & 4.4 \\
Neutral detergent & 18.2 & 20.5 & 36.8 \\
fiber & 53.9 & 51.1 & 32.8 \\
Non-fibrous & 18.6 & 18.5 & 18.4 \\
carbohydrates $^{2}$ & Gross energy $^{3}$ & &
\end{tabular}

${ }^{1} \mathrm{CON}$ : typical commercial concentrate rich in starch and based on cereals and soybean meal. CAM: typical commercial concentrate, which replaces $50 \%$ of soybean meal with camelina meal. FIB: concentrate rich in neutral detergent fiber, based on fibrous by-products and not including cereals or soybean meal. ${ }^{2}$ Calculated as (100-ash-crude protein-crude fat-neutral detergent fiber). ${ }^{3}$ Calculated as described by Ramin and Huhtanen [11].

Table 2. Mean ( \pm standard deviation), minimum (Min) and maximum (Max) contents of fatty acids quantified in the Longissimus thoracis muscle of lambs fed the experimental diets that were selected to be included in the study. Data expressed as $g$ per $100 \mathrm{~g}$ of total fatty acids.

\begin{tabular}{|c|c|c|c|c|c|c|c|c|c|}
\hline \multirow{3}{*}{ Parameters } & \multicolumn{9}{|c|}{ Treatments $^{1}$} \\
\hline & \multicolumn{3}{|c|}{$\mathrm{CON}$} & \multicolumn{3}{|c|}{ CAM } & \multicolumn{3}{|c|}{ FIB } \\
\hline & Mean & Min & Max & Mean & Min & Max & Mean & Min & Max \\
\hline C15:0 & $0.34 \pm 0.06$ & 0.28 & 0.40 & $0.32 \pm 0.01$ & 0.31 & 0.33 & $0.24 \pm 0.04$ & 0.21 & 0.31 \\
\hline C17:0 & $1.45 \pm 0.24$ & 1.19 & 1.76 & $1.34 \pm 0.06$ & 1.24 & 1.39 & $0.84 \pm 0.12$ & 0.75 & 1.05 \\
\hline $\mathrm{C} 14: 0$ iso & $0.34 \pm 0.05$ & 0.28 & 0.39 & $0.24 \pm 0.03$ & 0.20 & 0.27 & $0.23 \pm 0.04$ & 0.18 & 0.28 \\
\hline $\mathrm{C} 17: 0$ iso & $0.14 \pm 0.03$ & 0.10 & 0.18 & $0.13 \pm 0.02$ & 0.10 & 0.15 & $0.14 \pm 0.04$ & 0.10 & 0.19 \\
\hline C17:0 anteiso & $0.27 \pm 0.05$ & 0.21 & 0.33 & $0.45 \pm 0.04$ & 0.41 & 0.51 & $0.44 \pm 0.07$ & 0.36 & 0.56 \\
\hline Cis-11 C18:1 & $2.06 \pm 0.22$ & 1.79 & 2.25 & $2.14 \pm 0.11$ & 2.00 & 2.29 & $1.57 \pm 0.11$ & 1.47 & 1.76 \\
\hline Trans-10 C18:1 & $3.33 \pm 1.22$ & 1.20 & 4.21 & $4.77 \pm 0.56$ & 3.90 & 5.35 & $4.54 \pm 0.98$ & 3.60 & 5.81 \\
\hline Trans-11 C18:1 & $0.67 \pm 0.06$ & 0.59 & 0.76 & $1.26 \pm 0.20$ & 1.03 & 1.50 & $3.59 \pm 0.62$ & 3.25 & 4.70 \\
\hline Trans-11,cis-15 C18:2 & $0.04 \pm 0.01$ & 0.03 & 0.05 & $0.22 \pm 0.02$ & 0.21 & 0.25 & $0.27 \pm 0.04$ & 0.23 & 0.33 \\
\hline Cis-9,trans-11 18:2 & $0.18 \pm 0.04$ & 0.14 & 0.24 & $0.28 \pm 0.05$ & 0.24 & 0.35 & $0.79 \pm 0.18$ & 0.59 & 1.08 \\
\hline Trans-10,cis-12 C18:2 & $0.10 \pm 0.01$ & 0.09 & 0.11 & $0.10 \pm 0.01$ & 0.09 & 0.11 & $0.08 \pm 0.00$ & 0.08 & 0.08 \\
\hline
\end{tabular}

${ }^{1} \mathrm{CON}$ : typical commercial concentrate rich in starch and based on cereals and soybean meal. CAM: typical commercial concentrate, which replaces $50 \%$ of soybean meal with camelina meal. FIB: concentrate rich in neutral detergent fiber based on fibrous by-products and not including cereals or soybean meal.

$\mathrm{CH}_{4}$ production was calculated using three equations developed for ruminants in general: Equation (13) of Ramin and Huhtanen [11], the equation of Bell et al. [27] and Equation (4) of Sauvant et al. [28]. The predictors in these equations are feeding level or DMI relative to $\mathrm{BW}$, organic matter digestibility (OMD) or digestible organic matter in dry matter (DOM), and the contents of ether extract, neutral detergent fibre and non-fibrous carbohydrates in dry matter basis. Since Equation (13) of Ramin and Huhtanen [11] reports $\mathrm{CH}_{4}$ as kJ per MJ of GE, the result was multiplied by GE intake in MJ/d and divided by the conversion factor $55.65 \mathrm{~kJ} / \mathrm{g}$ to obtain $\mathrm{CH}_{4}$ production in $\mathrm{g} / \mathrm{d}$. GE intake was calculated from diet GE and DMI. DOM was calculated by multiplying OMD by organic matter in dry matter. 
For stablishing OMD, we conducted a digestion assay at the Animal Nutrition Experimental Centre at the University of Murcia. A total of $15 \mathrm{rams}(40.2 \pm 2.3 \mathrm{~kg}$ and $7.8 \pm 0.6$ months old) kept in individual $1.5 \mathrm{~m}^{2}$ straw-bedded pens provided with individual feed and water throughs were used. Rams were randomly allocated to one of the three experimental treatments detailed above ( 5 replicates per treatment). Dietary concentrates (CON, CAM and FIB) and barley straw were offered ad libitum during 21 days. The adaptation period lasted 15 days and the collection period 6 days. Then, the ratio concentrate:straw was kept at 95:5 and the diet was offered at $90 \%$ of the intake registered the previous week to avoid refusals. Titanium dioxide $\left(\mathrm{TiO}_{2}\right)$ was used as an inert marker [29]. Five grams of $\mathrm{TiO}_{2}$ per $\mathrm{kg}$ were added to the batch of each experimental concentrate in the mixer before pelletizing at the same commercial feed mill. Representative subsamples of each batch were collected, and aliquots were mixed to obtain a composite sample for each concentrate. Individual feces were sampled directly from the rectum, by hand protected by a single-use latex glove, on three alternate days of the 6-day collection period, just before morning feeding. Aliquots of the three subsamples from each lamb were mixed in a composite sample and kept in plastic zip bags that were stored at $-20^{\circ} \mathrm{C}$ until analysis. Organic matter in feed and feces was determined by the difference between the dry matter content after drying in an oven until constant weight and the ash concentration after incineration in a muffle furnace. Quantification of $\mathrm{TiO}_{2}$ in feeds and feces was done following the procedure of Myers et al. [30]. Then, OMD was calculated with the following formula: $\mathrm{OMD}(\%)=\left[1-\left(\mathrm{M}_{\text {feed }} / \mathrm{M}_{\text {feces }}\right) /\left(\mathrm{OM}_{\text {feces }} / \mathrm{OM}_{\text {feed }}\right] \times 100\right.$; where $\mathrm{M}_{\text {feed }}$ and $\mathrm{M}_{\text {feces }}$ are the concentrations of $\mathrm{TiO}_{2}$ in feed and feces dry matter, and $\mathrm{OM}_{\mathrm{feces}}$ and $\mathrm{OM}_{\text {feed }}$ are the concentrations of organic matter in feces and feed dry matter.

SAS University Edition 3.8 (SAS Institute, Cary, NC, USA) was used for the statistical analysis. The GLM procedure was used to investigate differences between dietary treatments in OMD, DMI relative to $\mathrm{BW}$ and calculated $\mathrm{CH}_{4}$ production. Experimental treatments were the fixed effect in the statistical model. When the model was significant, differences between least squared means were investigated with Tukey's test. Stepwise regression analysis in the GLMSELECT procedure was used to investigate the relationship between calculated $\mathrm{CH}_{4}$ production and the contents of specific FA in lambs IMF. The best model was chosen according to the PRESS option (minimum true prediction error through leave-one-out validation). Model performance was assessed by the adjusted coefficient of determination $\left(\mathrm{R}^{2}{ }_{\mathrm{adj}}\right)$, the root of the mean square of prediction error (RMSPE), the RMSPE expressed as proportion of the observed mean (\%RMSPE), and the concordance correlation coefficient (CCC). Furthermore, the mean square of prediction error (MSPE) was decomposed into mean bias (measure of precision), slope bias (measure of accuracy), and random error [12]. Pearson's correlation was used when appropriate. Statistical significance was declared at $p<0.05$.

\section{Results and Discussion}

The eleven FA selected for the statistical regression analysis (Table 2) were selected because they directly relate to rumen bacteria metabolism $[25,26]$. From a quantitative point of view, these FA are the most important of their respective groups, accounting for more than $60 \%$ of total FA within each group (i.e., linear odd, iso and anteiso FA groups, and cis and trans C18 isomer groups). Linear odd, iso and anteiso FA are synthesized by rumen bacteria and incorporated into their lipid membranes to maintain fluidity and cell membrane function [31]. On the other hand, cis and trans isomers of C18:1 and C18:2 FA are produced by bacteria in the ruminal biohydrogenation process from unsaturated lipids consumed in the diet [32]. Several FA included in the statistical analysis (C17:0 iso, cis-11 C18:1, trans-10 C18:1 and trans-11, cis-15 C18:2) have been previously related to $\mathrm{CH}_{4}$ production in dairy cows $[13,14]$.

Lambs' average BW during the fattening period was $19.8 \pm 0.74 \mathrm{~kg}$ and did not differ between dietary treatments [19]. FIB concentrate exhibited lower OMD and higher feeding level $(p<0.05)$ when compared to $\mathrm{CON}$ and $\mathrm{CAM}$ rations. Accordingly, calculated $\mathrm{CH}_{4}$ 
production in the FIB group was lower than CON and CAM treatments $(p<0.05)$ (Table 3). It is worth mentioning that $\mathrm{CH}_{4}$ production calculated with the three equations was highly correlated $(r=0.90$ to $0.98, p<0.001$ ). However, this similarity does not necessarily imply that the predictions of those equations are accurate. Moreover, it has been pointed out that equations to predict $\mathrm{CH}_{4}$ production in sheep need refinement [33], which increases the significance of our approach to predict methane production from meat FA profile.

Table 3. Apparent in vivo organic matter digestibility (OMD, \%) and digestible organic matter (DOM, $\%$ dry matter) of the diets at maintenance feeding level, and dry matter intake (DMI, $\mathrm{kg} / \mathrm{d}$ ), actual feeding level ( $\mathrm{g}$ dry matter intake/ $\mathrm{kg}$ body weight) and calculated methane $\left(\mathrm{CH}_{4}\right)$ production $(\mathrm{g} / \mathrm{d})$ of lambs according to Ramin and Huhtanen [11], Bell et al. [27] and Sauvant et al. [28].

\begin{tabular}{cccccc}
\hline \multirow{2}{*}{ Parameters } & \multicolumn{3}{c}{ Treatments $^{\mathbf{1}}$} & \multirow{2}{*}{ SEM $^{2}$} & $p$ \\
\cline { 2 - 4 } & CON & CAM & FIB & & \\
\hline OMD & $76.7^{\mathrm{a}}$ & $77.2^{\mathrm{a}}$ & $66.4^{\mathrm{b}}$ & 1.41 & $<0.001$ \\
$\mathrm{DOM}$ & $71.8^{\mathrm{a}}$ & $71.7^{\mathrm{a}}$ & $60.4^{\mathrm{b}}$ & 1.49 & $<0.001$ \\
$\mathrm{DMI}$ & $0.80^{\mathrm{b}}$ & $0.77^{\mathrm{b}}$ & $0.96^{\mathrm{a}}$ & 0.03 & $<0.001$ \\
$\mathrm{DMI} / \mathrm{kg} \mathrm{BW}$ & $40.9^{\mathrm{b}}$ & $38.2^{\mathrm{b}}$ & $48.5^{\mathrm{a}}$ & 1.31 & $<0.001$ \\
$\mathrm{CH}_{4}[11]$ & $14.7^{\mathrm{a}}$ & $14.5^{\mathrm{a}, \mathrm{b}}$ & $13.3^{\mathrm{b}}$ & 0.24 & $<0.001$ \\
$\mathrm{CH}_{4}[27]$ & $16.1^{\mathrm{a}}$ & $16.0^{\mathrm{a}}$ & $13.0^{\mathrm{b}}$ & 0.43 & $<0.001$ \\
$\mathrm{CH}_{4}[28]$ & $12.5^{\mathrm{a}}$ & $12.4^{\mathrm{a}}$ & $10.4^{\mathrm{b}}$ & 0.30 & $<0.001$ \\
\hline
\end{tabular}

${ }^{1}$ CON: typical commercial concentrate rich in starch and based on cereals and soybean meal. CAM: typical commercial concentrate, which replaces $50 \%$ of soybean meal with camelina meal. FIB: concentrate rich in neutral detergent fiber based on fibrous by-products and not including cereals or soybean meal. ${ }^{2}$ Standard error of the mean. ${ }^{a, b}$ Least squared means without a common superscript are significantly different by Tukey's test at $p<0.05$.

Several equations have been developed to predict $\mathrm{CH}_{4}$ production specifically in sheep $[9,10,34]$ or across ruminant species $[11,27,28,35]$. The three equations used in the present study (Table 3) fitted our data well. All of them rely on knowing OMD and present different levels of complexity according to the number of predictors used. The simplest model is Equation (4) of Sauvant et al. [28], which only takes into account DOM and feeding level. The equations of Ramin and Huhtanen [11] and Bell et al. [27] include feeding level and percentage of crude fat in the diet dry matter as predictors. The latter [27] also includes DOM at maintenance feeding level as a predictor whereas the former incorporates OMD at maintenance feeding level and the contents of neutral detergent fibre and non-fibrous carbohydrates in diet dry matter. Diet digestibility and feeding level play a pivotal role in the prediction of $\mathrm{CH}_{4}$ emissions by ruminants. However, the influence of carbohydrate and fat contents in the diet has been documented and should also be considered. Increasing diet digestibility, mainly through improved fibrous carbohydrate digestibility, increases $\mathrm{CH}_{4}$ emission, while increasing feeding level and dietary fat decrease it [35-38].

The best regression models obtained in the present study for predicting $\mathrm{CH}_{4}$ production from FA profiles, as shown in Table 2, are presented in Equations (1)-(3), respectively. In the statistical models to derive Equations (1)-(3), $\mathrm{CH}_{4}$ production was calculated according to Equation (13) of Ramin and Huhtanen [11], the equation of Bell et al. [27] and Equation (4) of Sauvant et al. [28], respectively.

$$
\begin{gathered}
\mathrm{CH}_{4}(\mathrm{~g} / \mathrm{d})=19.06( \pm 1.917)+1.74( \pm 0.735) \times \mathrm{C} 17: 0-3.10( \pm 0.861) \times \text { cis-11 C18:1-1.07 }( \pm 0.260) \times \text { trans }-11 \mathrm{C} 18: 1 \\
+5.36( \pm 2.112) \times \text { trans-11, cis-15 C18:2 } \\
\mathrm{R}^{2}{ }_{\text {adj }}=0.74 ; \mathrm{RMSPE}=0.40 \mathrm{~g} / \mathrm{d} ; \% \mathrm{RMSPE}=2.83 \% ; \mathrm{CCC}=0.89 \\
\mathrm{CH}_{4}(\mathrm{~g} / \mathrm{d})=24.50( \pm 2.282)+2.43( \pm 0.695) \times \mathrm{C} 17: 0-11.09( \pm 2.462) \times \mathrm{C} 14: 0 \text { iso-13.51 }( \pm 4.698) \times \mathrm{C} 17: 0 \text { iso- } 2.62 \\
( \pm 0.726) \times \text { cis }-11 \mathrm{C} 18: 1-1.36( \pm 0.191) \times \text { trans }-11 \mathrm{C} 18: 1 \\
\mathrm{R}^{2}{ }_{\text {adj }}=0.93 ; \mathrm{RMSPE}=0.34 \mathrm{~g} / \mathrm{d} ; \% \mathrm{RMSPE}=2.28 \% ; \mathrm{CCC}=0.98
\end{gathered}
$$




$$
\begin{gathered}
\mathrm{CH}_{4}(\mathrm{~g} / \mathrm{d})=15.22( \pm 1.372)-11.95( \pm 3.425) \times \mathrm{C} 17: 0 \text { iso }+4.18( \pm 1.165) \times \mathrm{C} 17: 0 \text { anteiso-0.80 }( \pm 0.556) \times \text { cis-11 } \\
\text { C18:1-1.03 }( \pm 0.138) \times \text { trans }-11 \text { C18:1 } \\
\mathrm{R}^{2}{ }_{\text {adj }}=0.91 ; \mathrm{RMSPE}=0.29 \mathrm{~g} / \mathrm{d} ; \% \mathrm{RMSPE}=2.51 \% ; \mathrm{CCC}=0.96
\end{gathered}
$$

In all equations fatty acids are $\mathrm{g} / 100 \mathrm{~g}$ of total fatty acids.

Equation (2) was slightly better than the others in terms of precision, accuracy and reproducibility, according to $\mathrm{R}^{2}$ adj, RMSPE, \%RMSPE and CCC values, respectively, but the three models performed very well. Moreover, their high precision and accuracy was supported by the fact that none of the models showed mean or linear bias, with nearly $100 \%$ of MSE due to random error. The best single predictor in Equations (1)-(3) was trans-11 C18:1 $\left(R^{2}=0.51,0.78\right.$ and 0.78 , respectively), whereas the weakest predictors were $\mathrm{C} 17: 0\left(\mathrm{R}^{2}\right.$ improvement $\left.=13.6 \%\right), \mathrm{C} 14: 0$ iso $\left(\mathrm{R}^{2}\right.$ improvement $\left.=4.2 \%\right)$ and cis-11 C18:1 $\left(\mathrm{R}^{2}\right.$ improvement $=1.1 \%$ ) in Equations (1)-(3), respectively. These results may be supported by the fact that previous studies in dairy cattle have found negative relationships between methane emissions and the contents of cis-11 C18:1, trans-11 C18:1 and C17:0 iso in milk fat, whereas C17:0 anteiso showed a positive relationship [13,14,39,40]. In contrast to our results, a negative relationship between trans-11, cis-15 C18:2 and methane emissions has been observed $[13,14,39]$. The role of $\mathrm{C} 17: 0$ has been reported as positive with regard to $\mathrm{CH}_{4}$ yield and negative with regard to $\mathrm{CH}_{4}$ production $[14,39,40]$.

Unfortunately, published papers on $\mathrm{CH}_{4}$ emissions of lambs that simultaneously report a detailed meat FA profile are scant. Therefore, in order to challenge our approach, we constructed a database with diet composition, average DMI and BW, and intramuscular FA profile of lambs from previous published works [41-43]. Then, we derived the OMD at maintenance levels in their diets from tabulated data of feed composition [44] and calculated $\mathrm{CH}_{4}$ production in two ways: (i) using Equation (4) of Sauvant et al. [28] (Table 4) and (ii) using intramuscular FA contents in Equation (3) of the present study, scaled to BW to include BW effects on DMI (Table 5). Equation (3) was chosen over Equation (2) because one publication did not report C14:0 iso contents in intramuscular fat [42]. It is important to note that [41-43] included about $6 \%$ of highly unsaturated oils in their studies, which is known to have a great impact on the intramuscular FA profile due to its effects on ruminal fermentation $[45,46]$.

Table 4. Apparent organic matter digestibility (OMD, \%) and digestible organic matter (DOM, \% dry matter) of the diets at maintenance feeding level, body weight (BW, kg), dry matter intake (DMI, $\mathrm{kg} / \mathrm{d})$, actual feeding level ( $\mathrm{g}$ dry matter intake/ $\mathrm{kg}$ body weight), and calculated methane $\left(\mathrm{CH}_{4}\right)$ production $(\mathrm{g} / \mathrm{d})$ of lambs allocated to several experimental treatments in the studies of Costa et al. [41], Oliveira et al. [42] and Santos-Silva et al. [43].

\begin{tabular}{ccccccc}
\hline Treatments $^{1}$ & OMD & DOM & BW & DMI & DMI/kg BW & CH $_{\mathbf{4}}{ }^{\mathbf{2}}$ \\
\hline Costa et al. [41] & & & & & & \\
CON & 77.7 & 71.6 & 33.4 & 1.18 & 35.3 & 22.4 \\
DCP & 80.8 & 72.9 & 32.7 & 1.23 & 37.6 & 22.8 \\
DBP & 78.3 & 70.5 & 34.8 & 1.31 & 37.7 & 23.5 \\
SH & 77.5 & 70.5 & 33.6 & 1.28 & 38.1 & 22.8 \\
Oliveira et al. [42] & & & & & & \\
MSMD & 80.9 & 74.9 & 27.3 & 1.1 & 40.4 & 19.9 \\
MSHD & 80.3 & 74.0 & 25.3 & 0.99 & 39.1 & 18.1 \\
HSMD & 82.6 & 77.0 & 26.4 & 0.88 & 33.3 & 18.6 \\
HSHD & 82.3 & 76.7 & 26.9 & 0.93 & 34.6 & 19.1 \\
Santos-Silva et al. [43] & & & & & & \\
MA & 79.0 & 71.5 & 30.9 & 1.35 & 43.8 & 21.9 \\
HA & 74.6 & 66.8 & 30.9 & 1.47 & 47.6 & 20.5 \\
\hline
\end{tabular}

${ }^{1}$ CON: control. DBP: dehydrated beet sugar pulp. DCP: dehydrated citrus pulp. HA: high alfalfa. HSHD: high-starch, high-degradability. HSMD: high-starch, mid rumen degradability. LA: low alfalfa. MA: medium alfalfa. MSHD: mid-starch, high rumen degradability. MSMD: mid-starch, mid rumen degradability. SH: soybean hulls. ${ }^{2}$ Calculated with Equation (4) of Sauvant et al. [28]. 
Table 5. Intramuscular FA contents and calculated methane production $\left(\mathrm{CH}_{4}, \mathrm{~g} / \mathrm{d}\right)$ of lambs allocated to several experimental treatments in the studies of Costa et al. [41], Oliveira et al. [42] and SantosSilva et al. [43]. Data expressed as g per $100 \mathrm{~g}$ of total fatty acids.

\begin{tabular}{cccccc}
\hline Treatments $^{1}$ & C17:0 iso & $\begin{array}{c}\text { C17:0 } \\
\text { anteiso }\end{array}$ & Cis-11 18:1 & Trans-11 18:1 CH $^{{ }^{2}}$ \\
\hline Costa et al. [41] & & & & & \\
CON & 0.20 & 0.30 & 1.41 & 0.91 & 21.1 \\
DCP & 0.17 & 0.23 & 1.27 & 1.77 & 19.5 \\
DBP & 0.18 & 0.33 & 1.39 & 1.62 & 21.3 \\
SH & 0.27 & 0.32 & 1.29 & 3.56 & 15.3 \\
Oliveira et al. [42] & & & & & \\
MSMD & 0.19 & 0.31 & 1.33 & 0.69 & 17.9 \\
MSHD & 0.20 & 0.34 & 1.29 & 0.72 & 16.6 \\
HSMD & 0.15 & 0.38 & 1.42 & 0.58 & 18.5 \\
HSHD & 0.21 & 0.35 & 1.34 & 0.66 & 17.6 \\
Santos-Silva et al. & & & & & \\
[43] & 0.19 & 0.30 & 1.18 & 0.91 & 20.0 \\
LA & 0.19 & 0.27 & 1.06 & 1.67 & 18.7 \\
MA & 0.22 & 0.30 & 1.11 & 2.32 & 16.9 \\
HA & & & & & \\
\hline
\end{tabular}

${ }^{1}$ CON: control. DBP: dehydrated beet sugar pulp. DCP: dehydrated citrus pulp. HA: high alfalfa. HSHD: high-starch, high-degradability. HSMD: high-starch, mid rumen degradability. LA: low alfalfa. MA: medium alfalfa. MSHD: mid-starch, high rumen degradability. MSMD: mid-starch, mid rumen degradability. SH: soybean hulls. ${ }^{2}$ Calculated with Equation (3) of the present study and scaled to average body weight (i.e., calculated value was multiplied by the ratio average body weight in the study/19.8).

It was found that calculated $\mathrm{CH}_{4}$ with Equation (4) of Sauvant et al. [28] (Table 4) and Equation (3) of the present study (Table 5) were correlated $(\mathrm{r}=0.52)$, although statistical significance was not reached $(p=0.10)$ due to the low calculated value of $\mathrm{CH}_{4}$ production with Equation (3) in the SH diet of Costa et al. [41]. Such a low value was derived from the high trans-11 C18:1 content in the SH treatment, which was three-fold higher than the average trans-11 C18:1 level in other treatments of that study (Table 5). Nevertheless, the results of the comparison supported the relationship between calculated $\mathrm{CH}_{4}$ production and intramuscular FA profile and encouraged us to develop a new and more generalizable regression equation including both our own data and those from Costa et al. [41], Oliveira et al. [42] and Santos-Silva et al. [43] (Tables 2-5). In this new statistical model (Equation (4)), calculated $\mathrm{CH}_{4}$ production with Equation (4) of Sauvant et al. [28] was the variable, C17:0 iso, C17:0 anteiso, cis-11 18:1, trans-11 18:1 and average BW were the predictors, and the regression was weighted by the squared root of the number of observations in each experimental treatment.

$\mathrm{CH}_{4}(\mathrm{~g} / \mathrm{d})=-1.98( \pm 1.284)-0.87( \pm 0.231) \times$ trans $-11 \mathrm{C} 18: 1+0.79( \pm 0.045) \times$ body weight
$\mathrm{R}^{2}{ }_{\text {adj }}=0.97 ; \mathrm{RMSPE}=0.76 \mathrm{~g} / \mathrm{d} ; \% \mathrm{RMSPE}=4.04 \% ; \mathrm{CCC}=0.98$

Trans-11 C18:1 is expressed in $\mathrm{g} / 100$ of total fatty acids and body weight is expressed in $\mathrm{kg}$.

The intercept in Equation (4) did not reach statistical significance $(p=0.15)$ but both predictors were significant $(p<0.01)$. Our model showed high precision, accuracy and reproducibility, supported by excellent $\mathrm{R}^{2}{ }_{\text {adj }}$, RMSPE, \%RMSPE and CCC values, and the fact that nearly $100 \%$ of MSE was due to random error. Equation (4) supports the important role of the ruminal biohydrogenation intermediate trans-11 C18:1 as a predictor of $\mathrm{CH}_{4}$, which would be related to the fact that trans- $11 \mathrm{C} 18: 1$ is strongly related to the composition of the diet $[20,41,43]$. Although several assumptions had to be made in the construction of the model, the obtained results substantiated a general relationship between $\mathrm{CH}_{4}$ production and intramuscular FA profile in lambs, best explained taking into account the BW of the animals considered (Equation (4)). The effect of BW on $\mathrm{CH}_{4}$ production has been previously described in growing sheep [47]. 
In general, prediction models of $\mathrm{CH}_{4}$ production in ruminants are derived from studies where data were obtained with laboratory techniques that might not resemble what occurs under farming conditions [48]. The present model is even more limited since $\mathrm{CH}_{4}$ production was indirectly calculated and only data from lambs raised under intensive feeding conditions were used, which precludes its applicability to lambs fed in pastures or high forage systems. Clearly, there is a need for more studies that simultaneously report measures of $\mathrm{CH}_{4}$ production and intramuscular FA composition of lambs raised not only in feedlots but also in other feeding systems in order to develop more reliable and applicable predictive models of $\mathrm{CH}_{4}$ production.

\section{Conclusions}

The equations obtained in the present study might be potentially useful to account for the environmental impact of lambs raised under intensive farming conditions. These results support that specific intramuscular FA and average BW during fattening could be used to predict $\mathrm{CH}_{4}$ production in lambs. More studies would be needed to develop robust prediction models of $\mathrm{CH}_{4}$ production from intramuscular FA in lambs.

Author Contributions: Conceptualization, F.R.D. and A.L.M.M.; methodology, A.L.M.M., F.H. and M.Á.d.l.F.; validation, F.H. and A.L.M.M.; formal analysis, A.L.M.M.; investigation, F.R.D., P.G.-C., S.M.-M.; resources, F.H. and A.L.M.M.; data curation, P.G.-C., F.H. and A.L.M.M.; writing-original draft preparation, F.R.D. and A.L.M.M.; writing—review and editing, A.L.M.M., M.Á.d.l.F., P.G.-C., and F.H.; visualization, F.R.D. and A.L.M.M.; supervision, P.G.-C., M.Á.d.l.F., and A.L.M.M.; project administration, M.Á.d.l.F., A.L.M.M. and F.H. All authors have read and agreed to the published version of the manuscript.

Funding: This research was funded by CDTI and CRIN Smart Growth Operating Program FEDER 2014-2020 (grant number INALSA IDI-20160001) as well as the Spanish Ministry of Economy and Competitiveness (project number AGL2016-75159-C2-2-R). P. G-C benefited from a Ramón y Cajal research contract (RYC2019-027933-I) and funding from the Spanish National Research Council (20217AT002).

Institutional Review Board Statement: Ethical review and approval for the zootechnical procedures described in this study were waived due to the fact that Spanish legislation does not require it because they were undertaken for the purposes of recognized animal husbandry. Digestibility assay was approved by the Ethics Committee of Universidad de Murcia (protocol code A13171003).

Data Availability Statement: The data presented in this study are available in the article.

Acknowledgments: Iniciativas Alimentarias S. A. (Ciudad Real, Spain) is gratefully acknowledged for providing the experimental concentrates.

Conflicts of Interest: The authors declare no conflict of interest. The funders had no role in the design of the study; in the collection, analyses, or interpretation of data; in the writing of the manuscript, or in the decision to publish the results.

\section{References}

1. Gerber, P.J.; Steinfeld, H.; Henderson, B.; Mottet, A.; Opio, C.; Dijkman, J.; Falcucci, A.; Tempio, G. Tackling Climate Change through Livestock-A Global Assessment of Emissions and Mitigation Opportunities; Food and Agriculture Organization: Rome, Italy, 2013.

2. Schultz, M.M.; Neser, F.W.; Makgahlela, M.L. A balanced perspective on the importance of extensive ruminant production for human nutrition and livelihoods and its contribution to greenhouse gas emissions. S. Afr. J. Sci. 2020, 116, 1-3. [CrossRef]

3. Morgavi, D.P.; Forano, E.; Martin, C.; Newbold, C.J. Microbial ecosystem and methanogenesis in ruminants. Animal 2010, 4, 1024-1036. [CrossRef] [PubMed]

4. Huhtanen, P.; Ramin, M.; Cabezas-Garcia, E.H. Effects of ruminal digesta retention time on methane emissions: A modelling approach. Anim. Prod. Sci. 2016, 56, 501-506. [CrossRef]

5. Van Gastelen, S.; Dijkstra, J.; Bannink, A. Are dietary strategies to mitigate enteric methane emission equally effective across dairy cattle, beef cattle, and sheep? J. Dairy Sci. 2019, 102, 6109-6130. [CrossRef] [PubMed]

6. Hristov, A.N.; Oh, J.; Firkins, J.L.; Dijkstra, J.; Kebreab, E.; Waghorn, G.; Makkar, H.P.S.; Adesogan, A.T.; Yang, W.; Lee, C.; et al. Mitigation of methane and nitrous oxide emissions from animal operations: I. A review of enteric methane mitigation options. J. Anim. Sci. 2013, 91, 5045-5069. [CrossRef] 
7. Escobar-Bahamondes, P.; Oba, M.; Beauchemin, K.A. Universally applicable methane prediction equations for beef cattle fed high- or low-forage diets. Can. J. Anim. Sci. 2017, 97, 83-94. [CrossRef]

8. Patra, A.K.; Lalhriatpuii, M. Development of statistical models for prediction of enteric methane emission from goats using nutrient composition and intake variables. Agric. Ecosyst. Environ. 2016, 215, 89-99. [CrossRef]

9. Patra, A.K.; Lalhriatpuii, M.; Debnath, B.C. Predicting enteric methane emission in sheep using linear and non-linear statistical models from dietary variables. Anim. Prod. Sci. 2016, 56, 574. [CrossRef]

10. Pelchen, A.; Peters, K.J. Methane emissions from sheep. Small Rumin. Res. 1998, 27, 137-150. [CrossRef]

11. Ramin, M.; Huhtanen, P. Development of equations for predicting methane emissions from ruminants. J. Dairy Sci. 2013, 96, 2476-2493. [CrossRef]

12. Santiago-Juárez, B.; Moraes, L.E.; Appuhamy, J.A.D.R.N.; Pellikaan, W.F.; Casper, D.P.; Tricarico, J.; Kebreab, E. Prediction and evaluation of enteric methane emissions from lactating dairy cows using different levels of covariate information. Anim. Prod. Sci. 2016, 56, 557. [CrossRef]

13. Bougouin, A.; Appuhamy, J.A.D.R.N.; Ferlay, A.; Kebreab, E.; Martin, C.; Moate, P.J.; Benchaar, C.; Lund, P.; Eugène, M. Individual milk fatty acids are potential predictors of enteric methane emissions from dairy cows fed a wide range of diets: Approach by meta-analysis. J. Dairy Sci. 2019, 102, 10616-10631. [CrossRef]

14. Castro-Montoya, J.M.; Peiren, N.; Veneman, J.; De Baets, B.; De Campeneere, S.; Fievez, V. Predictions of methane emission levels and categories based on milk fatty acid profiles from dairy cows. Animal 2017, 11, 1153-1162. [CrossRef] [PubMed]

15. Requena, F.; Peña, F.; Agüera, E.; Martínez Marín, A.L. A meta-analytic approach to predict methane emissions from dairy goats using milk fatty acid profile. Sustainability 2020, 12, 4834. [CrossRef]

16. van Lingen, H.J.; Crompton, L.A.; Hendriks, W.H.; Reynolds, C.K.; Dijkstra, J. Meta-analysis of relationships between enteric methane yield and milk fatty acid profile in dairy cattle. J. Dairy Sci. 2014, 97, 7115-7132. [CrossRef]

17. Negussie, E.; de Haas, Y.; Dehareng, F.; Dewhurst, R.J.; Dijkstra, J.; Gengler, N.; Morgavi, D.P.; Soyeurt, H.; van Gastelen, S.; Yan, T.; et al. Large-scale indirect measurements for enteric methane emissions in dairy cattle: A review of proxies and their potential for use in management and breeding decisions. J. Dairy Sci. 2017, 100, 2433-2453. [CrossRef]

18. Gómez-Cortés, P.; Requena Domenech, F.; Correro Rueda, M.; de la Fuente, M.A.; Schiavone, A.; Martínez Marín, A.L. Odd- and branched-chain fatty acids in lamb meat as potential indicators of fattening diet characteristics. Foods 2021, 10, 77. [CrossRef]

19. Avilés Ramírez, C.; Peña Blanco, F.; Horcada, A.; Núñez Sánchez, N.; Requena Domenech, F.; Guzmán Medina, P.; Martínez Marín, A.L. Effects of concentrates rich in by-products on growth performance, carcass characteristics and meat quality traits of light lambs. Anim. Prod. Sci. 2019, 59, 593-599. [CrossRef]

20. Gómez-Cortés, P.; Galisteo, O.O.; Avilés Ramirez, C.; Peña Blanco, F.; de la Fuente, M.A.; Núñez Sánchez, N.; Martínez Marín, A.L. Intramuscular fatty acid profile of feedlot lambs fed concentrates with alternative ingredients. Anim. Prod. Sci. 2019, 59, 914-920. [CrossRef]

21. AOAC. Official Methods of Analysis, 17th ed.; Association of Official Analytical Chemists: Washington, DC, USA, 2000.

22. Van Soest, P.J.; Robertson, J.B.; Lewis, B.A. Methods for dietary fiber, neutral detergent fiber, and nonstarch polysaccharides in relation to animal nutrition. J. Dairy Sci. 1991, 74, 3583-3597. [CrossRef]

23. Blanco, C.; Bodas, R.; Prieto, N.; Andrés, S.; López, S.; Giráldez, F.J. Concentrate plus ground barley straw pellets can replace conventional feeding systems for light fattening lambs. Small Rumin. Res. 2014, 116, 137-143. [CrossRef]

24. Bligh, E.G.; Dyer, W.J. A rapid method of total lipid extraction and purification. Can. J. Biochem. Physiol. 1959, 37, 911-917. [CrossRef]

25. Jenkins, T.C.; Wallace, R.J.; Moate, P.J.; Mosley, E.E. Recent advances in biohydrogenation of unsaturated fatty acids within the rumen microbial ecosystem. J. Anim. Sci. 2008, 86, 397-412. [CrossRef] [PubMed]

26. Vlaeminck, B.; Fievez, V.; Cabrita, A.R.J.; Fonseca, A.J.M.; Dewhurst, R.J. Factors affecting odd- and branched-chain fatty acids in milk: A review. Anim. Feed Sci. Technol. 2006, 131, 389-417. [CrossRef]

27. Bell, M.; Eckard, R.; Moate, P.; Yan, T. Modelling the effect of diet composition on enteric methane emissions across sheep, beef cattle and dairy cows. Animals 2016, 6, 54. [CrossRef]

28. Sauvant, D.; Giger-Reverdin, S.; Serment, A.; Broudiscou, L. Influences des régimes et de leur fermentation dans le rumen sur sa production de méthane par les ruminants. Prod. Anim. 2011, 24, 433-446. [CrossRef]

29. Guzmán-Cedillo, A.E.; Corona, L.; Castrejón-Pineda, F.; Rosiles-Martínez, R.; González-Ronquillo, M. Evaluation of chromium oxide and titanium dioxide as inert markers for calculating apparent digestibility in sheep. J. Appl. Anim. Res. 2017, 45, 275-279. [CrossRef]

30. Myers, W.D.; Ludden, P.A.; Nayigihugu, V.; Hess, B.W. Technical note: A procedure for the preparation and quantitative analysis of samples for titanium dioxide. J. Anim. Sci. 2004, 82, 179-183. [CrossRef]

31. Or-Rashid, M.M.; Odongo, N.E.; Mcbride, B. Fatty acid composition of ruminal bacteria and protozoa, with emphasis on conjugated linoleic acid, vaccenic acid, and odd-chain and branched-chain fatty acids. J. Anim. Sci. 2007, 85, 1228-1234. [CrossRef] [PubMed]

32. Shingfield, K.J.; Wallace, R.J. Chapter 1. Synthesis of conjugated linoleic acid in ruminants and humans. In Conjugated Linoleic Acids and Conjugated Vegetable Oils; Royal Society of Chemistry: London, UK, 2014; pp. 1-65. 
33. Benaouda, M.; Martin, C.; Li, X.; Kebreab, E.; Hristov, A.N.; Yu, Z.; Yáñez-Ruiz, D.R.; Reynolds, C.K.; Crompton, L.A.; Dijkstra, J.; et al. Evaluation of the performance of existing mathematical models predicting enteric methane emissions from ruminants: Animal categories and dietary mitigation strategies. Anim. Feed Sci. Technol. 2019, 255, 114207. [CrossRef]

34. Ma, T.; Deng, K.; Diao, Q. Prediction of methane emission from sheep based on data measured in vivo from open-circuit respiratory studies. Asian-Australas. J. Anim. Sci. 2019, 32, 1389-1396. [CrossRef] [PubMed]

35. Blaxter, K.L.; Clapperton, J.L. Prediction of the amount of methane produced by ruminants. Br. J. Nutr. 1965, 19, 511-522. [CrossRef] [PubMed]

36. Grainger, C.; Beauchemin, K.A. Can enteric methane emissions from ruminants be lowered without lowering their production? Anim. Feed Sci. Technol. 2011, 166-167, 308-320. [CrossRef]

37. Moe, P.W.; Tyrrell, H.F. Methane production in dairy cows. J. Dairy Sci. 1979, 62, 1583-1586. [CrossRef]

38. Patra, A.K. A meta-analysis of the effect of dietary fat on enteric methane production, digestibility and rumen fermentation in sheep, and a comparison of these responses between cattle and sheep. Livest. Sci. 2014, 162, 97-103. [CrossRef]

39. Chilliard, Y.; Martin, C.; Rouel, J.; Doreau, M. Milk fatty acids in dairy cows fed whole crude linseed, extruded linseed, or linseed oil, and their relationship with methane output. J. Dairy Sci. 2009, 92, 5199-5211. [CrossRef] [PubMed]

40. Dijkstra, J.; van Zijderveld, S.M.; Apajalahti, J.A.; Bannink, A.; Gerrits, W.J.J.; Newbold, J.R.; Perdok, H.B.; Berends, H. Relationships between methane production and milk fatty acid profiles in dairy cattle. Anim. Feed Sci. Technol. 2011, 166-167, 590-595. [CrossRef]

41. Costa, M.; Alves, S.P.; Francisco, A.; Almeida, J.; Alfaia, C.M.; Martins, S.V.; Prates, J.A.M.; Santos-Silva, J.; Doran, O.; Bessa, R.J.B. The reduction of starch in finishing diets supplemented with oil does not prevent the accumulation of trans-10 18:1 in lamb meat. J. Anim. Sci. 2017, 95, 3745-3761. [CrossRef] [PubMed]

42. Oliveira, M.A.; Alves, S.P.; Santos-Silva, J.; Bessa, R.J.B. Effect of dietary starch level and its rumen degradability on lamb meat fatty acid composition. Meat Sci. 2017, 123, 166-172. [CrossRef]

43. Santos-Silva, J.; Francisco, A.; Alves, S.P.; Portugal, P.; Dentinho, T.; Almeida, J.; Soldado, D.; Jerónimo, E.; Bessa, R.J.B. Effect of dietary neutral detergent fibre source on lambs growth, meat quality and biohydrogenation intermediates. Meat Sci. 2019, 147, 28-36. [CrossRef]

44. INRA. Alimentation des Bovins, Ovins et Caprins. Besoins des Animaux. Valeur des Aliments; Editions Quae: Versailles, France, 2007.

45. Ferreira, E.M.; Pires, A.V.; Susin, I.; Gentil, R.S.; Parente, M.O.M.; Nolli, C.P.; Meneghini, R.C.M.; Mendes, C.Q.; Ribeiro, C.V.D.M. Growth, feed intake, carcass characteristics, and meat fatty acid profile of lambs fed soybean oil partially replaced by fish oil blend. Anim. Feed Sci. Technol. 2014, 187, 9-18. [CrossRef]

46. Li, F.; Zhang, Z.; Li, X.; Zhu, B.; Guo, L.; Li, F.; Weng, X. Effect of duration of linseed diet supplementation before slaughter on the performances, meat fatty acid composition and rumen bacterial community of fattening lambs. Anim. Feed Sci. Technol. 2020, 263, 114457. [CrossRef]

47. Zhou, Y.; Dong, L.F.; Deng, K.D.; Xu, G.S.; Diao, Q.Y. Development of models of methane emissions from growing sheep. Sci. Agric. Sin. 2019, 52, 1797-1806. [CrossRef]

48. Storm, I.M.L.D.; Hellwing, A.L.F.; Nielsen, N.I.; Madsen, J. Methods for measuring and estimating methane emission from ruminants. Animals 2012, 2, 160-183. [CrossRef] [PubMed] 